\title{
Mobile phone support to sustain exclusive breastfeeding in the community after hospital delivery and counseling: a quasi- experimental study
}

Iftia Jerin ${ }^{1,2}$, Monira Akter ${ }^{1 *}$, Khurshid Talukder ${ }^{1}$, Muhammad Qudrat e Khuda Talukder ${ }^{1}$ and Mohammad Abdur Rahman ${ }^{3}$

\begin{abstract}
Background: Rapid increases in hospital and cesarean deliveries threaten an already falling exclusive breastfeeding rate (EBR) in Bangladesh. There is neither a sustained Baby-Friendly Hospital Initiative (BFHI) nor any community support for breastfeeding mothers. Our aim was to find out whether breastfeeding support after hospital delivery and subsequently by mobile phone at home is effective in improving EBR in infants under six-months of age.

Methods: A quasi-experimental study was carried out in 2010 at the Centre for Woman and Child Health (CWCH), Savar, Bangladesh. A total of 129 mothers delivered at CWCH were recruited in pre-intervention phase and their infants followed up between 0 and 5 months of age in the community for exclusive breastfeeding (EBF), anthropometry and illness. An intervention package was then implemented with postpartum support for first hour breastfeeding initiation, correction of position and attachment and face-to-face counseling in hospital followed by mobile phone support by two trained Research Assistants once every 15 days after discharge up to six months of age. During the intervention phase, 164 pregnant women delivered at CWCH were recruited and followed up as in the pre-intervention phase.
\end{abstract}

Results: In the pre-intervention phase among 114 infants, 66 (58\%) were found to be exclusively breastfed. In the intervention phase among 151 infants, $118(78 \%)$ were exclusively breastfed $(p=0.000)$. In the pre-intervention phase EBR at less than one month and five months were 85 and $42 \%$ as in the intervention phase these EBR were 89 and 71\% respectively. Wasting (weight-for-height Z-score $<-2.00$ ), stunting (height-for-age Z-score $<-2.00$ ), and underweight (weight-for-age Z-score $<-2.00$ ) was 17 (15\%), 7 (6\%), and $14(13 \%)$ respectively in the preintervention phase. In the intervention phase wasting, stunting, and underweight was 16 (11\%), 16 (11\%), and 15 (10\%) respectively. Therefore, there was no statistically significant differences in nutritional status of the infants in the two phases. There was also no significant differences in child morbidity (pneumonia and diarrhea) between the two phases.

Conclusion: A combination of hospital support and mobile phone counseling in the community sustained higher rates of EBF in the community after hospital delivery.

Keywords: Exclusive breastfeeding, Bangladesh, Breastfeeding initiation, Counseling, Mobile phone

\footnotetext{
* Correspondence: monira.akter03@yahoo.com

${ }^{1}$ Centre for Woman and Child Health (CWCH), Savar, Dhaka 1349, Bangladesh

Full list of author information is available at the end of the article
}

(c) The Author(s). 2020 Open Access This article is licensed under a Creative Commons Attribution 4.0 International License, which permits use, sharing, adaptation, distribution and reproduction in any medium or format, as long as you give appropriate credit to the original author(s) and the source, provide a link to the Creative Commons licence, and indicate if changes were made. The images or other third party material in this article are included in the article's Creative Commons licence, unless indicated otherwise in a credit line to the material. If material is not included in the article's Creative Commons licence and your intended use is not permitted by statutory regulation or exceeds the permitted use, you will need to obtain permission directly from the copyright holder. To view a copy of this licence, visit http://creativecommons.org/licenses/by/4.0/. The Creative Commons Public Domain Dedication waiver (http://creativecommons.org/publicdomain/zero/1.0/) applies to the data made available in this article, unless otherwise stated in a credit line to the data. 


\section{Background}

Breastfeeding is the best means of optimal nutrition, growth, development and survival for infants and young children $[1,2]$. It is now well established that suboptimal breastfeeding is associated with increased risks of malnutrition [3-5], morbidity [6, 7] and mortality [8-11] in children, especially in low- and middle-income countries.

In Bangladesh, there has been a fivefold increase in facility-based deliveries from $9 \%$ in 2001 to $47 \%$ in 2016 [12]. Since 1992, 499 out of 670 maternity units in the country had achieved baby friendly status under the BabyFriendly Hospital Initiative (BFHI) but frequent turnover of trained health personnel, lack of refresher training and weak implementation of the Breast Milk Substitute (BMS) Act were major contributing factors for significant deterioration $[13,14]$ in breastfeeding promotion. This was further compounded by non-existent support for lactating mothers in the community after discharge. All these threaten an already declining annual exclusive breastfeeding rate (EBR - in previous $24 \mathrm{~h}$ ) in infants below six months of age of (64\%, in 2011 and 65\% in 2014) and this decline is further compounded by an undesirable high rate of cesarean sections, $65 \%$ of all facility deliveries in 2016 [12]. In private hospitals the rate was $83 \%$, in NonGovernment Organization (NGO) hospitals 39\% and, in public hospitals 35\% [12]. A recent Bangladeshi study [15] as well as a systematic review [16] has found strong evidence that cesarean section can impede exclusive breastfeeding (EBF).

A systematic review [17] of global breastfeeding programs showed that despite poor overall study quality, structured programs had an impact on breastfeeding performance. A Cochrane review [18] that analyzed trials of support for breastfeeding showed an increased EBR at six-months. Support was more effective when it was in the setting of antenatal and postnatal care, took place during planned points of contact, and adapted to local needs. Support was also more successful in populations with high initiation rates and when it was provided through interpersonal communication.

Another Cochrane review [19], which documented results from seven trials of breastfeeding support by telephone, suggested that such support could increase breastfeeding duration. This review noted that providing telephone support for breastfeeding increased EBF at six months. A study in Nigeria [20] showed that breastfeeding related text messages were effective in improving EBR at six months. Another study in India [21] showed that mobile phone and text message interventions for lactation support improved EBF measured at multiple points of time. Together, these studies suggest that breastfeeding messaging or support offered by mobile phone could potentially be a low cost strategy for improving breastfeeding practices in a variety of settings.
Our theoretical framework for this study is that, although high rates of EBF are possible by promotion in hospitals at delivery and in the immediate postnatal period by trained personnel, these rates are rapidly eroded due to lack of structured support in the community $[22,23]$. We hypothesize that facility based trained personnel can continue to provide outreach breastfeeding counseling services in the community by mobile phone and sustain EBF effectively (Fig. 1).

Based on the above, we carried out a quasi-experimental study with the objective of evaluating the impact on EBR of facility based breastfeeding promotion of delivering mothers followed by fortnightly mobile phone breastfeeding counseling calls at home for six months after discharge. Other outcomes of interest were infant illness and anthropometry.

This quasi-experimental study was designed to assess whether a package of face-to-face and phone based breastfeeding promotion and support leads to increase in EBR in infants below six months of age following hospital delivery. This is important in a low middle-income country like Bangladesh where hospital-based deliveries and cesarean sections are increasing rapidly.

\section{Methods \\ Design}

In this quasi-experimental study EBR was assessed in young infants aged 0 and 180 days of age post-delivery in the community in serially recruited pre and postintervention phases of postnatal mothers without randomization to intervention.

\section{Setting}

Mother-infant pairs delivered at the Centre for Woman and Child Health $(\mathrm{CWCH})$, a secondary level health facility $28 \mathrm{~km}$ to the north-west of Dhaka Metropolitan Area in Bangladesh, were studied immediately after delivery as well as in the community after discharge between April and December 2010. Almost all infants delivered at this hospital are breastfed within one hour of delivery. This coupled with $93 \%$ breastfeeding prevalence in infants at 9-11 months nationally [24] ensured that recruitment took place in no more than three months of each phase of the study.

\section{Intervention}

A curriculum was developed by a participatory method involving the hospital's research team, lactation management team, obstetrician/gynecologists (OB/GYN), pediatric physicians and maternity registered nurses (RN). The curriculum also incorporated features from international literature on Infant and Young Child Feeding (IYCF) training for health personnel [25-30]. Initially a one-day orientation training session was conducted for 


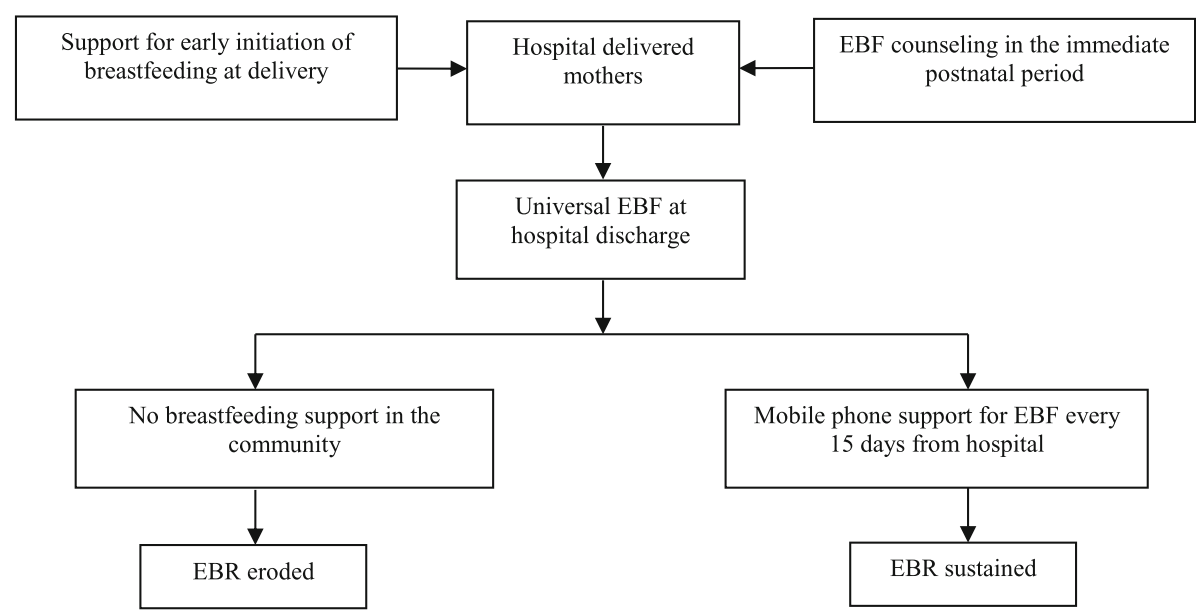

Fig. 1 Theoretical framework for sustaining EBF in the Community by mobile phone promotion

$\mathrm{CWCH}$ physicians from the $\mathrm{OB} / \mathrm{GYN}$ and Pediatric departments and RNs by a nutritionist and lactation consultant, both of whom were female. They were given in-depth understanding of benefits of first hour initiation of breastfeeding; disadvantages of late initiation of breastfeeding, techniques of first hour initiation of breastfeeding, in both normal and cesarean deliveries, barriers to initiation of breastfeeding in the first hour and how to overcome those barriers.

Five maternity RN from $\mathrm{CWCH}$ and two Research Assistants (RA) then received a three-day training course on breastfeeding, which included basic information on breastfeeding, counseling and support techniques as well as practical sessions on observation and assessment of breastfeeding and counseling in the hospital. Topics covered included, (i) importance and basic features of breastfeeding, (ii) techniques of breastfeeding, (iii) milk expression, (iv) common problems of the breasts during breastfeeding and their solution and (v) counseling skills on breastfeeding with emphasis on listening, learning, building confidence and giving support, specially the avoidance of judging words to prevent maternal guilt and blame. Training methods included lectures, handson demonstration, and practical exercises with real-life postpartum breastfeeding mothers in hospital and videoguided lessons. The two female trainers observed each trainee $\mathrm{RN}$ while assessing a new breastfeeding mother, using a structured checklist.

Trained maternity personnel (RNs under guidance from the lactation consultant and $\mathrm{CWCH}$ physicians) ensured early initiation of breastfeeding immediately after birth for all mother-infant pairs. For intervention mothers, RNs also assessed position and attachment of the infant within $24 \mathrm{~h}$ and corrected any problem detected by repeated face-to-face tailor-made support of both mothers and attending relatives. In addition, RNs also promoted appropriate IYCF practices in a counseling class for intervention mothers and their relatives during their stay in hospital. This class covered advantages of breastfeeding, dangers of formula feeding, how to ensure EBF up to six months of age, advantages of EBF, common breast problems during breastfeeding and their solutions, family support for EBF, how to express breast milk during infant's illness and how to start complementary food after six months. These classes were conducted within $48 \mathrm{~h}$ of birth for cesarean deliveries and $24 \mathrm{~h}$ for vaginal deliveries.

After discharge from hospital, intervention mother-infant pairs were followed up (Table 1) by mobile phone counseling calls every 15 days by two trained RAs up to six months of age. These calls followed a structured interview protocol. During the calls, which lasted for approximately $15 \mathrm{~min}$, the mother was asked what she was feeding her infant, confirming that not even water was given to those infants whose mothers said that they were feeding nothing but human milk. If the response was EBF, she congratulated the mother and advised her to continue this good practice up to six months of age, avoiding even feeding water. If the mother was not exclusively breastfeeding, then the RA asked her why she was not. If the reason given was inadequate human milk then the RA asked her about the infant's urine output and weight gain, emphasizing that colorless urine passed more than six times a day and weight gain were signs that human milk was adequate. She also re-emphasized the importance of position and attachment, which had been demonstrated during the hospital admission. Finally, she reiterated the advantages of EBF and the dangers of formula feeding. If the mother still expressed doubts about her ability to exclusively breastfeed, the RA advised consultation with the lactation consultant in the $\mathrm{CWCH}$. 
Table 1 Mobile phone support during community follow up by Research Assistant

\begin{tabular}{|c|c|}
\hline Problem & Solution provided \\
\hline Inadequate human milk & $\begin{array}{l}\text { Signs of getting enough human } \\
\text { milk - } \\
\text { - urine passed } 6-8 \text { times in } 24 \mathrm{~h} \\
\text { - urine is not yellow but is clear } \\
\text { - weight gain } 500 \mathrm{~g} \text { per month }\end{array}$ \\
\hline Crying baby & $\begin{array}{l}\text { - Crying is the baby's only language } \\
\text { - Value of a full breastfeed - foremilk } \\
\text { and hindmilk } \\
\text { - Proper breastfeeding position and } \\
\text { attachment }\end{array}$ \\
\hline $\begin{array}{l}\text { Baby does not take mother's } \\
\text { breast }\end{array}$ & $\begin{array}{l}\text { Proper breastfeeding position and } \\
\text { attachment }\end{array}$ \\
\hline $\begin{array}{l}\text { Breastfeeding is hard and mother } \\
\text { doesn't have the energy }\end{array}$ & $\begin{array}{l}\text { - Benefits of human milk for child } \\
\text { - Benefits of human milk for mother } \\
\text { - Value of a full breastfeed - foremilk } \\
\text { and hindmilk }\end{array}$ \\
\hline Working mother & $\begin{array}{l}\text { - Human milk expression } \\
\text { - Human milk storage } \\
\text { - Feeding human milk with a } \\
\text { spoon/cup } \\
\text { - Disadvantages and dangers of } \\
\text { formula/processed milk }\end{array}$ \\
\hline $\begin{array}{l}\text { Different types of breast problems } \\
\text { like engorgement, blocked duct, } \\
\text { sore nipple, inverted nipple }\end{array}$ & $\begin{array}{l}\text { Consultation with the lactation } \\
\text { consultant at } \mathrm{CWCH}\end{array}$ \\
\hline
\end{tabular}

\section{Sample}

Mothers were recruited in this study by a Research Assistant (RA) who collected data regarding patient identity, delivery and postnatal care from the postnatal ward, usually the day after delivery at $\mathrm{CWCH}$. Eligibility criteria included all mothers who delivered in the hospital, intended to breastfeed within one hour of birth, planned to breastfeed infants exclusively, were resident in the study area for six months or more after delivery, and owned a mobile phone. Infants with apparent health problems, prematurity and extremely low birthweight $(<1000 \mathrm{~g})$, mothers with complicated cesarean sections and compromised maternal health were excluded because of the possible inability of the mother or infant to initiate breastfeeding.

Mothers recruited in the pre-intervention phase experienced routine breastfeeding support care in hospital immediately after delivery. The hospital did not have baby friendly status but maternity personnel would put the infant to breast within one hour of birth provided maternal and newborn clinical conditions (such as perinatal asphyxia) allowed this. There was no pro-active promotion and support of breastfeeding practices but problem-oriented support was provided to mothers for breastfeeding if it was requested. Examples of support provided would be assessment and correction of position and attachment, extra help for mothers with engorged breasts or sore nipples or for those who delivered by cesarean section.

\section{Data measures}

Exclusive breastfeeding rate is the proportion of under six-month old infants in a population who have been fed nothing but human milk in the $24 \mathrm{~h}$ prior to the interview. Accessing this information from uniformly distributed infants of different ages is not easy, especially if there is time constraint in data collection. We somewhat mitigated this difficulty by interviewing mothers in the community in reverse order to the time of discharge from hospital after delivery, as described in the data collection section below. Our questionnaire included a question asking the mother what she was currently feeding her infant. If she said only human milk then follow up questions were asked specifically about whether water, infant formula, animal milk or any other food was also given. This line of questioning has previously been validated in Bangladesh by stable isotope studies on infants whose mothers claimed that they had fed their infants exclusively on human milk for the previous $24 \mathrm{~h}$ [31].

\section{Data collection}

Pre-intervention data were collected for the first six months (April to September, 2010) of the study period by the RAs both in hospital and community using a structured questionnaire. During hospital data collection, delivery procedures and breastfeeding initiation practices in the labor room/operation theatre were documented. Neonatal details such as age, gender, gestational age, respiration, Apgar score, mode of delivery, any problems during birth and maternal medical details such as history of mother's medical and obstetric problems and other delivery related information were collected from medical records. Mothers were interviewed regarding sociodemographic characteristics, antenatal care, contraceptive use and perception about EBF. All information was collected within $48 \mathrm{~h}$ of delivery. Anthropometric measurement (height and weight) of mothers was done before delivery and of infants immediately after birth.

In order to assess EBR in the community infants enrolled in the pre-intervention phase were followed in "reverse order" in the community so that the last hospital recruited infants were visited first and the first recruited infants was visited last. In this way, we recruited a range of infants from seven to180 days of age. During home visits, mothers were asked about EBF and infant morbidity. Infant's weight and height were measured using a portable electronic baby scale accurate to $0.01 \mathrm{~kg}$ and a portable height scale accurate to one millimeter.

During the intervention phase (July to December, 2010), hospital data were collected for three months from recruited mother-infant pairs by using the same procedures and the same questionnaire as in the pre- 
intervention recruitment. After hospital discharge, these infants were followed in the community at less than six months of age by using the same "reverse order" mechanism and questionnaire as in the pre-intervention phase.

\section{Data analysis}

In the Bangladesh Demographic and Health Survey (BDHS) 2007 report [32], EBR was reported as $47 \%$ and we assumed that after intervention there would be a $25 \%$ point increase in EBR among intervention infants from this pre-intervention figure. This estimate was based on a randomized control trial [33], which showed EBF at five months was $70 \%$ after a community-based promotion of breastfeeding. We wanted to increase our EBR from an assumed rate of $47 \%$ in our study area to $70 \%$ (i.e. a $25 \%$ point increase). It was estimated that the sample size needed to detect differences between intervention and pre-intervention phases (with 0.05 alpha and $80 \%$ power) would be 103 mother-infant pairs in each phase, which was enhanced to 129 by expecting $25 \%$ lost to follow up in the study area. Data entry and validation was done using Epi-info and analysis was done using Statistical Package for the Social Sciences (SPSS) software. We compared sociodemographic parameters, delivery information, maternal factors, infant feeding practices, anthropometry [25] and illness data between the pre-intervention and intervention motherinfant pairs using the chi-square test. Mean number of family members and birthweight were compared by using Independent Samples $t$-test. Our main comparison of interest was EBR in the pre-intervention and intervention infants under six months of age.

\section{Results}

Mother-infant pairs were recruited and interviewed in the pre-intervention and intervention phases as shown in Fig. 2. Of the 151 deliveries that took place at $\mathrm{CWCH}$ in the pre-intervention recruitment phase (April-June 2010), 129 mothers were recruited for the study, 22 mother-infant pairs not fulfilling inclusion criteria. Out of the 129 mothers enrolled, 114 were found at the time of community follow up and therefore were included in this analysis. Of the 15 lost to follow up, three infants had died and another 12 mothers had moved back to their village homes. During the intervention recruitment phase (July-September 2010), there were 190 deliveries in the study hospital of which 164 mothers were enrolled, with 26 mother-infant pairs not recruited because they did not meet inclusion criteria. At the time of community follow up, 151 mother-infant pairs were located and these are the pairs included in the analysis. Among 13 families not located in follow up, three infants had died and 10 mothers had moved back to their village homes.

All intervention phase mothers received a breastfeeding promotion session in a class setting. They also all received a first assessment and correction (if needed) of position and attachment, followed by further few support sessions (if needed) for a select few. In the community, the number of fortnightly phone calls received by the mothers depended on the age of the baby by the end of the study. So, if the baby was only two weeks old

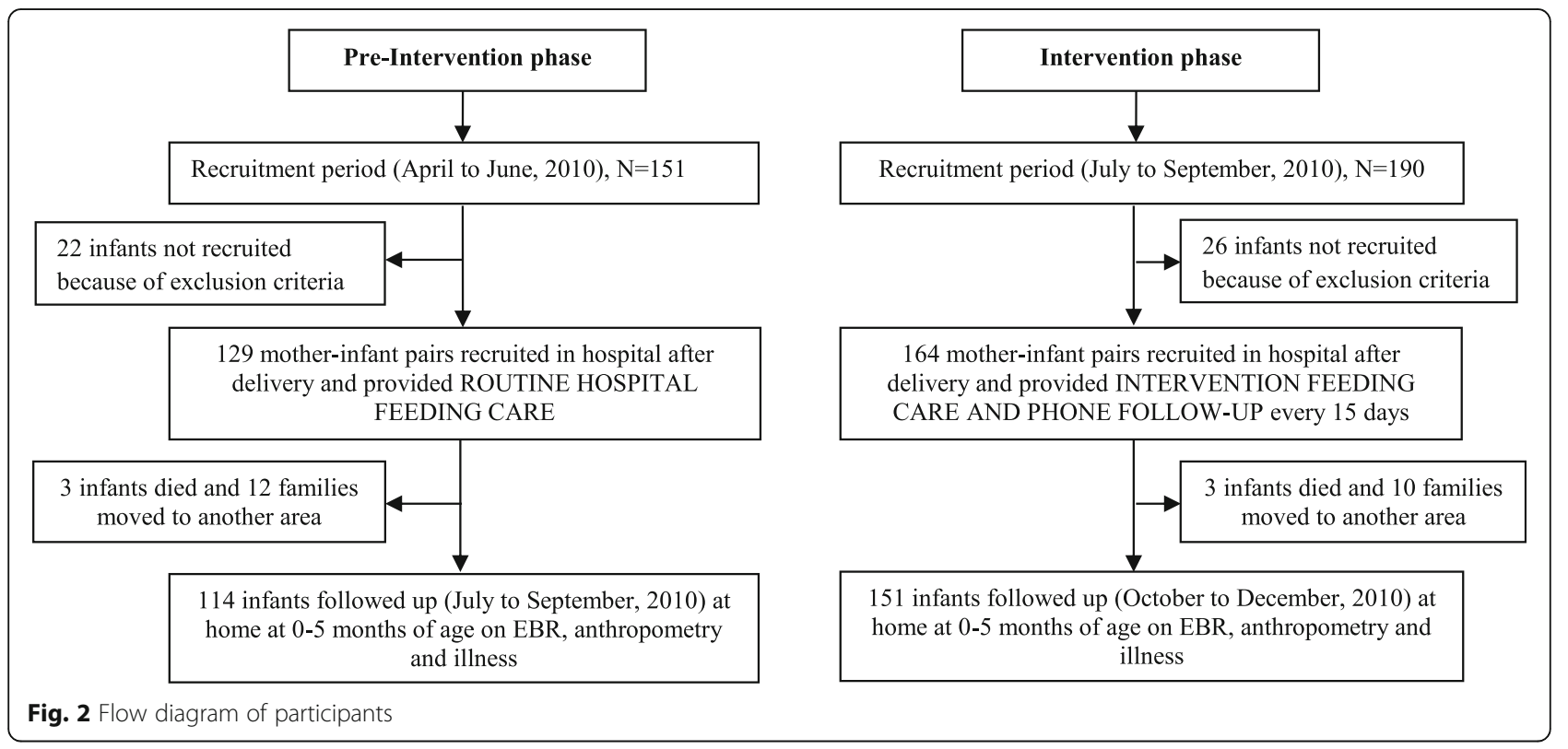


Table 2 Characteristics of participats by phase

\begin{tabular}{|c|c|c|c|}
\hline Background characteristics & Pre-intervention Phase $\boldsymbol{n}=114$ (\%) & Intervention Phase $\boldsymbol{n}=151$ (\%) & $\boldsymbol{p}$ - value $\mathrm{a}^{\mathbf{a}}$ \\
\hline \multicolumn{4}{|l|}{ Sociodemographic characteristics } \\
\hline \multicolumn{4}{|l|}{ Mother's educational qualification } \\
\hline Went to school & $112(98)$ & $145(96)$ & 0.47 \\
\hline Never went to school & $2(2)$ & $6(4)$ & \\
\hline \multicolumn{4}{|l|}{ Mother's occupation } \\
\hline Housewife & $99(87)$ & $132(87)$ & 1.00 \\
\hline Others & $15(13)$ & $19(13)$ & \\
\hline \multicolumn{4}{|l|}{ Age of the mother } \\
\hline$<20$ yrs & $16(14)$ & $15(10)$ & 0.44 \\
\hline $20-29 y r s$ & $88(77)$ & $116(77)$ & \\
\hline$\geq 30 \mathrm{yrs}$ & $10(9)$ & $19(13)$ & \\
\hline \multicolumn{4}{|l|}{ Father's educational qualification } \\
\hline Went to school & $112(98)$ & $147(97)$ & 0.70 \\
\hline Never went to school & $2(2)$ & $4(3)$ & \\
\hline \multicolumn{4}{|l|}{ Father's occupation } \\
\hline Manual worker & $20(18)$ & $39(26)$ & 0.14 \\
\hline Non-manual worker & $94(82)$ & $112(74)$ & \\
\hline \multicolumn{4}{|l|}{ Type of toilet facility } \\
\hline Sanitary & $109(96)$ & $146(97)$ & 0.75 \\
\hline Non-sanitary & $5(4)$ & $5(3)$ & \\
\hline \multicolumn{4}{|l|}{ Source of drinking water } \\
\hline Deep tube well & $114(100)$ & $148(98)$ & 0.26 \\
\hline Shallow tube well & $0(0)$ & $3(2)$ & \\
\hline \multicolumn{4}{|l|}{ Wealth index quintile } \\
\hline Poorest & $3(3)$ & $7(5)$ & 0.25 \\
\hline Middle & $71(62)$ & $101(67)$ & \\
\hline Richest & $40(35)$ & $43(28)$ & \\
\hline Mean number of family members & 3.97 & 4.45 & 0.11 \\
\hline \multicolumn{4}{|l|}{ Pregnancy characteristics } \\
\hline \multicolumn{4}{|l|}{ Gestational age } \\
\hline$<37$ weeks & $27(24)$ & $35(23)$ & 1.00 \\
\hline$\geq 37$ weeks & $87(76)$ & $116(77)$ & \\
\hline \multicolumn{4}{|l|}{ Mode of delivery } \\
\hline Vaginal & $22(19)$ & $46(30)$ & 0.05 \\
\hline Cesarean section & $92(81)$ & $105(70)$ & \\
\hline \multicolumn{4}{|l|}{ Outcome of pregnancy } \\
\hline Single & $110(97)$ & $151(100)$ & 0.47 \\
\hline Twin & $4(3)$ & $0(0)$ & \\
\hline \multicolumn{4}{|l|}{ Parity } \\
\hline Primipara & $61(54)$ & $73(48)$ & 0.46 \\
\hline Multipara & $53(46)$ & $78(52)$ & \\
\hline \multicolumn{4}{|l|}{ Infant characteristics } \\
\hline \multicolumn{4}{|l|}{ Gender of the Infant } \\
\hline Male & $68(60)$ & $83(55)$ & 0.45 \\
\hline
\end{tabular}


Table $\mathbf{2}$ Characteristics of participats by phase (Continued)

\begin{tabular}{llll}
\hline Background characteristics & Pre-intervention Phase $\boldsymbol{n}=114(\%)$ & Intervention Phase $\boldsymbol{n}=151(\%)$ & $\boldsymbol{p}-$ value $^{\mathbf{a}}$ \\
\hline \multicolumn{1}{c}{ Female } & $46(40)$ & $68(45)$ & 2892 \\
Mean birthweight (g) & 2784 & & 0.08 \\
$\begin{array}{l}\text { Feeding practice } \\
\text { Exclusive Breastfeeding Rate }\end{array}$ & $66(58)$ & $118(78)$ & 0.00 \\
\hline
\end{tabular}

${ }^{a} p$ - values were based on chi-square test

(near the end of the study) the mother will have received only one phone call. Those mothers whose babies were almost six months of age at the end of the study will have received a maximum of 12 phone calls.

When comparisons were made of sociodemographic, pregnancy and infant characteristics, there were no differences between these in the pre-intervention and intervention phases except EBR as described in Table 2, nor was there any significant difference $(p=$ 0.59 ) in age of infants between pre-intervention and intervention phases. Among pre-intervention infants, the EBR was $58 \%$ whilst in the intervention infants, this was $78 \%(p=0.000)$. Although infants ranging from 0 to 5 months were accessed by a method of community follow up of families in reverse order of discharge from hospital after delivery, this did not provide an equal number of infants in each age category (Fig. 3).

Exclusive breastfeeding remained at a high level in infants delivered in the intervention phase from $89 \%$ at less than one month to $71 \%$ at five months of age. In contrast, for the pre-intervention infants, EBF fell from $85 \%$ at less than one month to $42 \%$ at five months of age (Fig. 4).

There was no difference in prevalence of diarrhea and pneumonia between pre-intervention and intervention phase infants (Table 3).
There was no statistically significant difference between pre-intervention and intervention phases in prevalence of wasting (weight-for-height Z-score $<-2.00$ ), stunting (height-for-age Z-score $<-2.00$ ) or underweight (weight-for-age Z-score $<-2.00$ ) (Table 4).

\section{Discussion}

This study has shown that providing breastfeeding training to maternity personnel of a hospital to ensure first hour breastfeeding, assessment and correction of position and attachment, structured counseling of mothers of infants and their relatives on EBF followed by fortnightly mobile phone counseling at home increased EBR in the intervention phase $(78 \%)$ when compared to the pre-intervention phase $(58 \%)$, both matched for background characteristics $(p=0.000)$. Following discharge home, there was no significant difference in morbidity patterns and nutritional status between the two phases. Anthropometric parameters (wasting, stunting and underweight) were low for both groups compared to national figures [24] and are less likely to be affected by such a short intervention targeted to exclusive breastfeeding. A longer study involving counseling for appropriate complementary feeding in children aged 6-23 months would perhaps show a bigger difference between the two phases with regard to anthropometry.

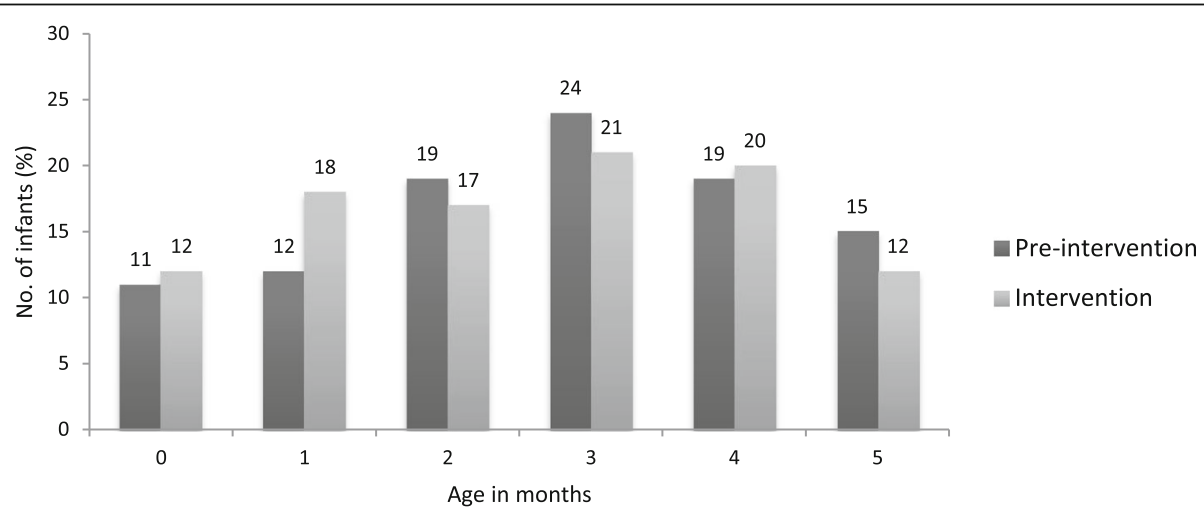

Fig. 3 Age distribution of infants followed up in the community in the Pre-intervention and Intervention Phase 


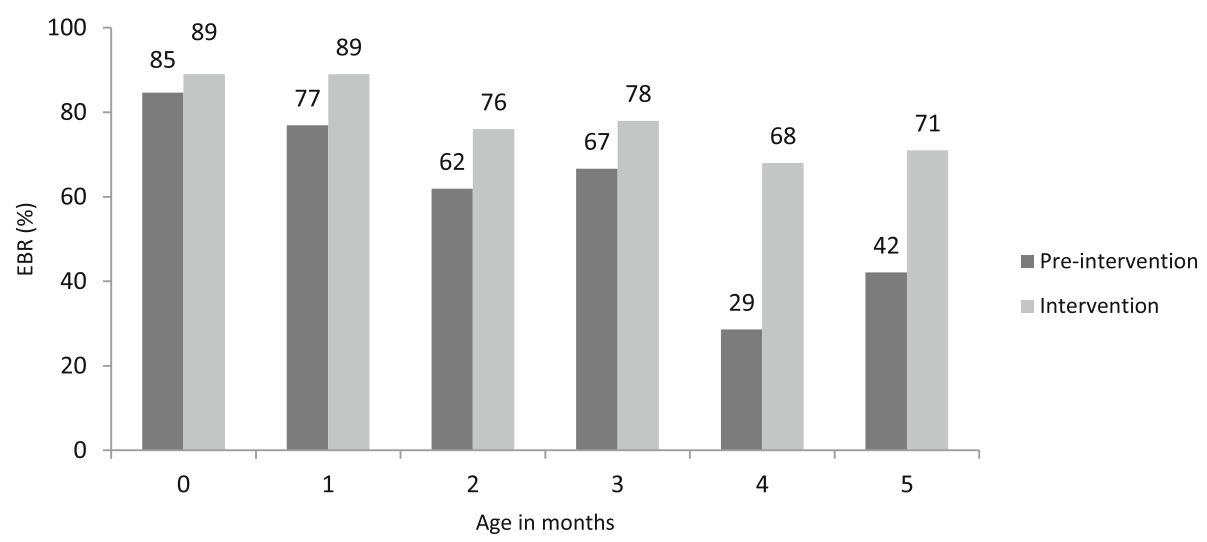

Fig. 4 Comparison of EBR between Pre-intervention and Intervention Phases by age of infants

The method of community follow up of mothers and their young infants, where the last discharged infant was followed up first and the first discharged infant was followed up last, meant that at assessment some mothers had received more counseling phone calls than others. This is acceptable because all studies show that EBF is lower in older infants in this age group, and therefore they would benefit from the increased number of phone calls which is clearly reflected in our study. At five months, large proportions of infants (71\%) in the intervention phase were still exclusively breastfed compared to those in the pre-intervention phase (42\%).

The pre-intervention infants were born between April and June 2010 (summer) and the intervention infants between July and September 2010 (monsoon). Although seasonality has been described as a factor which affects breastfeeding [34, 35], it is unclear in which way this happens. Some studies suggest decrease in the cold season and others in the wet season. Further cohort studies would clarify direction of association with regard to seasonality.

Our study demonstrates that use of mobile phone for follow up of hospital delivered infants for EBF counseling is an effective component of a behavior change communication intervention package. These study results are similar to those that increased breastfeeding duration and exclusivity by providing individual face-to-face counseling to mother or other caregiver [36-38].

EBF prevalence was much better in our study than in any previous study on proactive telephone breastfeeding support [39-47]. These previous studies were all done in high-income countries with much lower background breastfeeding prevalence than in Bangladesh, where continued breastfeeding rates are $95 \%$ at $9-11$ and $89 \%$ at 20-23 months of age [24]. Furthermore, previous community interventions without telephones in the country have shown that large increases in EBR are possible [48].

\section{Limitations}

This study design has limitations. Firstly, mother-infant pairs should have been randomly selected in both intervention and pre-intervention phases but budget constraints did not allow for this. This meant that the preintervention and intervention phase participants were not matched for season of birth nor for season of community follow up assessment and this may have had an influence on infant feeding. Secondly, the intervention was a package of hospital and community activities. This package included ensuring early initiation of breastfeeding within one hour of birth, followed by repeated face-

Table 3 Comparison of prevalence of diarrhea and pneumonia among pre-intervention and intervention Infants

\begin{tabular}{lll}
\hline Prevalence of diseases & Pre-intervention phase $\boldsymbol{n}=114(\%)$ & Intervention phase $\boldsymbol{n}=151(\%)$ \\
\hline $\begin{array}{l}\text { Diarrhea } \\
\text { Yes }\end{array}$ & $1(1)$ & $0(0)$ \\
No & $113(99)$ & $151(100)$ \\
Pneumonia & $1(1)$ & 0.43 \\
Yes & $113(99)$ & $0(0)$ \\
No & $151(100)$ & 0.43 \\
\hline
\end{tabular}

a $p$ - values were based on chi-square test 
Table 4 Assessment of difference in nutritional status between the two phases

\begin{tabular}{llll}
\hline Anthropometric parameter & Pre-intervention phase $\boldsymbol{n}=110(\%)$ & Intervention phase $\boldsymbol{n}=148(\%)$ & $\boldsymbol{p}-$ value $^{\mathbf{a}}$ \\
\hline Wasted $\left(\mathrm{WHZ}^{\mathrm{b}}<-2.00\right)$ & $17(15)$ & $16(11)$ & 0.35 \\
Stunted $\left(H A Z^{\mathrm{C}}<-2.00\right)$ & $7(6)$ & $16(11)$ & 0.27 \\
Underweight $\left(\mathrm{WAZ}^{\mathrm{d}}<-2.00\right)$ & $14(13)$ & $15(10)$ & 0.54 \\
\hline
\end{tabular}

${ }^{a} p$ - values were based on chi-square test

b Weight-for-height Z-score

${ }^{c}$ Height-for-age Z-score

${ }^{d}$ Weight-for-age Z-score

to-face support and counseling within $48 \mathrm{~h}$ of delivery. Thus, this study could not determine whether any single or a combination of these interventions is most effective. Furthermore, repeated phone calls to mothers in the community may have introduced an element of response bias where mothers felt pressure to respond positively when asked if they are exclusively breastfeeding at home follow-up questionnaire survey. This bias may have been further compounded by the same RAs both providing phone counseling as well as collecting research data. Future investigators may overcome this by separating these two functions.

\section{Conclusions}

This intervention package of multiple components including phone follow up for hospital delivered mothers to sustain EBF in the community led to increased EBR. This has large implications in a country where increasingly more women (50\% in 2017-18) are delivering in health facilities and there were 160 million mobile phone users in March 2019. Scaling up this intervention in existing baby friendly maternity facilities would lead to national increases in EBR and ultimately further reduction in child mortality. Further intervention studies are warranted to determine whether the promotion of appropriate complementary feeding in 6-23 month old children improves nutritional status.

\section{Abbreviations}

BFHI: Baby-Friendly Hospital Initiative; CWCH: Centre for Woman and Child Health; EBF: Exclusive Breastfeeding; EBR: Exclusive Breastfeeding Rate; IYCF: Infant and Young Child Feeding; NGO: Non-Government Organization; OB/GYN: Obstetrician/Gynecologist; RA: Research Assistant; RN: Registered Nurses

\section{Acknowledgments}

We would like to thank all the women who participated in the study. We thank Margarat Sarkar, lactation consultant from CWCH for her contribution to provide training to RAs. We also thank the trained CWCH RAs for their continuous support to delivered mothers.

\section{Authors' contributions}

IJ, KT, MQKT, and MAR made the conception and design the research protocol. IJ prepared the report and drafting the manuscript and with KT supervise the overall research activity. KT also gave critical revision and final approval of the manuscript. MA analyzed the research findings and prepared the draft and final manuscript. All authors read and approved the final manuscript.

\section{Authors' information}

1. Iftia Jerin, MS (Nutrition and Food Science), MPH, Senior Research Officer, Centre for Woman and Child Health (CWCH), Savar, Dhaka-1349, Bangladesh. Iftia Jerin is now Senior Project Officer at ENRICH, Nutrition International, Gulshan, Dhaka-1212, Bangladesh.

2. Monira Akter, MS (Food and Nutrition), Junior Scientist, Research

Department, Centre for Woman and Child Health (CWCH), Savar, Dhaka-1349, Bangladesh.

3. Khurshid Talukder, MBBS, DCH, MRCP, Director Research and Senior Consultant Pediatrician, Department of Pediatrics, Centre for Woman and

Child Health (CWCH), Savar, Dhaka-1349, Bangladesh.

4. Muhammad Qudrat e Khuda Talukder, MBBS, DCH, MRCP, FCPS, FRCP,

$\mathrm{PhD}$, Chairman, Centre for Woman and Child Health (CWCH), Savar, Dhaka1349, Bangladesh.

5. Mohammad Abdur Rahman, MBBS, MPH (RCH), MPH (PH Admin), PhD,

Professor, Department of public Health and Informatics, Jahangirnagar

University, Savar, Dhaka-1342, Bangladesh.

\section{Funding}

This research was supported by the Ministry of Science, Information and Communication Technology, Government of the People's Republic of Bangladesh and the Centre for Woman and Child Health, Savar, Bangladesh.

\section{Availability of data and materials}

The datasets used and/or analyzed during the current study are available from the corresponding author on reasonable request.

\section{Ethics approval and consent to participate}

This research protocol received ethical clearance from the CWCH Ethical Review Committee.

Before information was collected, informed verbal consent was taken from newly delivered mothers.

\section{Consent for publication}

Not applicable.

\section{Competing interests}

The authors declare that they have no competing interests.

\section{Author details}

${ }^{1}$ Centre for Woman and Child Health (CWCH), Savar, Dhaka 1349, Bangladesh. ${ }^{2}$ Nutrition International, Gulshan, Dhaka 1212, Bangladesh. ${ }^{3}$ Department of Public Health and Informatics, Jahangirnagar University, Savar, Dhaka 1342, Bangladesh.

Received: 8 March 2019 Accepted: 21 February 2020

Published online: 04 March 2020

\section{References}

1. Lawrence RA, Lawrence RM. Breastfeeding: a guide for the medical profession. 8th ed. Maryland Heights and Missouri: Elsevier Mosby; 2015.

2. Victora CG, Bahl R, Barros AJ, França GV, Horton S, Krasevec J, et al. Lancet breastfeeding series group. Breastfeeding in the 21st century: epidemiology, mechanisms, and lifelong effect. Lancet. 2016;387(10017):475-90.

3. Jones AD, Ickes SB, Smith LE, Mbuya MN, Chasekwa B, Heidkamp RA, et al. World Health Organization infant and young child feeding indicators and their associations with child anthropometry: a synthesis of recent findings. Matern Child Nutr. 2014;10(1):1-17. 
4. Menon P, Bamezai A, Subandoro A, Ayoya MA, Aguayo V. Age-appropriate infant and young child feeding practices are associated with child nutrition in India: insights from nationally representative data. Matern Child Nutr. 2015;11(1):73-87.

5. Lamichhane DK, Leem JH, Kim HC, Park MS, Lee JY, Moon SH, et al. Association of infant and young child feeding practices with undernutrition: evidence from the Nepal demographic and health survey. Paediatr Int Child Health. 2016;36(4):260-9.

6. Lamberti LM, Fischer Walker CL, Noiman A, Victora C, Black RE. Breastfeeding and the risk for diarrhea morbidity and mortality. BMC Public Health. 2011;11(Suppl 3):S15.

7. Lamberti LM, Zakarija-Grković I, Fischer Walker CL, Theodoratou E, Nair H, Campbell $\mathrm{H}$, et al. Breastfeeding for reducing the risk of pneumonia morbidity and mortality in children under two: a systematic literature review and meta-analysis. BMC Public Health. 2013;13(Suppl 3):S18.

8. Boccolini CS, Carvalho ML, Oliveira MI, Pérez-Escamilla R. Breastfeeding during the first hour of life and neonatal mortality. J Pediatr. 2013;89(2):131-6.

9. Debes AK, Kohli A, Walker N, Edmond K, Mullany LC. Time to initiation of breastfeeding and neonatal mortality and morbidity: a systematic review. BMC Public Health. 2013;13(Suppl 3):S19.

10. Sankar MJ, Sinha B, Chowdhury R, Bhandari N, Taneja S, Martines J, Bahl R. Optimal breastfeeding practices and infant and child mortality: a systematic review and meta-analysis. Acta Paediatr. 2015;104(467):3-13.

11. NEOVITA Study Group. Timing of initiation, patterns of breastfeeding, and infant survival: prospective analysis of pooled data from three randomized trials. Lancet Glob Health. 2016;4(4):e266-75.

12. National Institute of Population Research and Training (NIPORT) International Centre for Diarrhoeal Disease Research, Bangladesh (icddr,b), and MEASURE Evaluation. Bangladesh Maternal Mortality and Health Care Survey 2016: Preliminary Report. Dhaka, Bangladesh, and Chapel Hill: National Institute of Population Research and Training (NIPORT) International Centre for Diarrhoeal Disease Research, Bangladesh (icddr,b), and MEASURE Evaluation; 2017.

13. Bangladesh Breastfeeding Foundation. Project Completion Report: Revitalization of Baby Friendly Hospital Initiative (BFHI). Dhaka: Bangladesh Breastfeeding Foundation; 2016. Available from: http://bbf-bangladesh.org/ sites/default/files/BFHI\%20Project\%20Completion\%20Report.pdf.

14. World Health Organization. National Implementation of the Baby-friendly Hospital Initiative, Summary. Geneva: WHO; 2017. Available from: http:// www.who.int/iris/handle/10665/255198.

15. Khatun H, Comins CA, Shah R, Munirul Islam M, Choudhury N, Ahmed T. Uncovering the barriers to exclusive breastfeeding for mothers living in Dhaka's slums: a mixed method study. Int Breastfeed J. 2018;13:44.

16. Kavle JA, LaCroix E, Dau H, Engmann C. Addressing barriers to exclusive breast-feeding in low- and middle-income countries: a systematic review and programmatic implications. Public Health Nutr. 2017 Dec;20(17):312034.

17. Beake S, Pellowe C, Dykes F, Schmied V, Bick D. A systematic review of structured compared with non-structured breastfeeding programmes to support the initiation and duration of exclusive and any breastfeeding in acute and primary health care settings. Matern Child Nutr. 2012;8(2):141-61.

18. McFadden A, Gavine A, Renfrew MJ, Wade A, Buchanan P, Taylor JL, et al. Support for healthy breastfeeding mothers with healthy term babies. Cochrane Database Syst Rev. 2017;2:CD001141.

19. Lavender T, Richens Y, Milan SJ, Smyth RM, Dowswell T. Telephone support for women during pregnancy and the first six weeks postpartum. Cochrane Database Syst Rev. 2013;18(7):CD009338.

20. Flax VL, Negerie M, Ibrahim AU, Leatherman S, Daza EJ, Bentley ME. Integrating group counseling, cell phone messaging, and participantgenerated songs and dramas into a microcredit program increases Nigerian women's adherence to international breastfeeding recommendations. J Nutr. 2014;144(7):1120-4

21. Patel A. Effectiveness of cell phone counseling to improve breast feeding indicators (India). Presented at the meeting of IUNS $20^{\text {th }}$ International Congress of Nutrition, Granada (Spain). 15-20th September 2013.

22. Robert E, Michaud-Létourneau I, Dramaix-Wilmet M, Swennen B, Devlieger R. A comparison of exclusive breastfeeding in Belgian maternity facilities with and without Baby-friendly Hospital status. Matern Child Nutr. 2019; 15(4):e12845.

23. Mosher C, Sarkar A, Hashem AA, Hamadah RE, Alhoulan A, YA AM, et al. Self-reported breast feeding practices and the baby friendly hospital initiative in Riyadh, Saudi Arabia: prospective cohort study. BMJ Open. 2016; 6(12):e012890.

24. National Institute of Population Research and Training (NIPORT), Mitra and Associates, and ICF. Bangladesh Demographic and Health Survey 2017-18: Key Indicators. Dhaka, Bangladesh, and Rockville, Maryland, USA: National Institute of Population Research and Training, Mitra and Associates, and ICF: unpublished; 2018.

25. World Health Organization. WHO child growth standards: length/height-forage, weight-for-age, weight-for-length, weight-for-height and body mass index-for-age: methods and development. Geneva: Department of Nutrition for Health and Development, WHO: WHO; 2006. Available from: http://www who.int/childgrowth/standards/Technical_report.pdf.

26. World Health Organization and UNICEF. Infant and young child feeding counselling: an integrated course. Geneva: World Health Organization and UNICEF; 2006. Available from: https://www.who.int/nutrition/publications/ IYCF_Participants_Manual.pdf.

27. World Health Organization, UNICEF and Wellstart International. Baby-friendly hospital initiative: revised, updated and expanded for integrated care. Section 3, Breastfeeding promotion and support in a baby-friendly hospital: a 20-hour course for maternity staff. Geneva: WHO and UNICEF; 2009. Available from: https://www.unicef.org/nutrition/files/BFHI_2009_s3.1and2. pdf.

28. World Health Organization CDD Programme and UNICEF. Breastfeeding counseling: a training course trainer's guide. Part one Sessions 1-9. Geneva: WHO and UNICEF; 1993. Available from: https://www.who.int/maternal_ child_adolescent/documents/pdfs/bc_trainers_guide.pdf.

29. World Health Organization CDD programme and UNICEF. Breastfeeding counseling: a training course trainer's guide. Part two Sessions 10-19. Geneva: WHO and UNICEF; 1993. Available from: https://www.who.int/ nutrition/publications/bf_counselling_trainers_guide\%202.pdf.

30. World Health Organization CDD programme and UNICEF. Breastfeeding counseling: a training course trainer's guide. Part three Sessions 20-30. Geneva: WHO and UNICEF; 1993. Available from: https://www.who.int/ nutrition/publications/bf_counselling_trainers_guide\%203.pdf.

31. Moore SE, Prentice AM, Coward WA, Wright A, Frongillo EA, Fulford AJ, et al. Use of stable-isotope techniques to validate infant feeding practices reported by Bangladeshi women receiving breastfeeding counseling. Am J Clin Nutr. 2007:85(4):1075-82

32. National Institute of Population Research and Training (NIPORT), Mitra and Associates, and Macro International. Bangladesh Demographic and Health Survey 2007. Dhaka, Bangladesh and Calverton, Maryland, USA: National Institute of Population Research and Training, Mitra and Associates, and Macro International; 2009.

33. Haider R, Ashworth A, Kabir I, Huttly SR. Effect of community-based peer counsellors on exclusive breastfeeding practices in Dhaka, Bangladesh: a randomised controlled trial. Lancet. 2000;356(9242):1643-7.

34. González-Chica DA, Gonçalves H, Nazmi A, Santos IS, Barros AJ, Matijasevich A, Victora CG. Seasonality of infant feeding practices in three Brazilian birth cohorts. Int J Epidemiol. 2012;41(3):743-52.

35. Das A, Chatterjee R, Karthick M, Mahapatra T, Chaudhuri I. The influence of seasonality and community-based health worker provided counselling on exclusive breastfeeding - findings from a cross-sectional survey in India. PLoS One. 2016;11(8):e0161186.

36. Haroon S, Das JK, Salam RA, Imdad A, Bhutta ZA. Breastfeeding promotion interventions and breastfeeding practices: a systematic review. BMC Public Health. 2013;13(Suppl 3):S20

37. Rollins NC, Bhandari N, Hajeebhoy N, Horton S, Lutter CK, Martines JC, et al. Lancet breastfeeding series group. Why invest, and what it will take to improve breastfeeding practices? Lancet. 2016;387(10017):491-504.

38. Patnode CD, Henninger ML, Senger CA, Perdue LA, Whitlock EP. Primary care interventions to support breastfeeding: updated evidence report and systematic review for the US preventive services task force. JAMA. 2016; 316(16):1694-705.

39. Dennis CL, Hodnett E, Gallop R, Chalmers B. The effect of peer support on breast-feeding duration among primiparous women: a randomized controlled trial. CMAJ. 2002;166(1):21-8

40. Fallon AB, Hegney D, O'Brien M, Brodribb W, Crepinsek M, Doolan J. An evaluation of a telephone-based postnatal support intervention for infant feeding in a regional Australian city. Birth. 2005;32(4):291-8.

41. Graffy J, Taylor J. What information, advice, and support do women want with breastfeeding? Birth. 2005;32(3):179-86. 
42. Dennis CL, Kingston D. A systematic review of telephone support for women during pregnancy and the early postpartum period. J Obstet Gynecol Neonatal Nurs. 2008;37(3):301-14.

43. Bunik M, Shobe P, O'Connor ME, Beaty B, Langendoerfer S, Crane L, et al. Are 2 weeks of daily breastfeeding support insufficient to overcome the influences of formula? Acad Pediatr. 2010;10(1):21-8.

44. Meglio GD, McDermott MP, Klein JD. A randomized controlled trial of telephone peer support's influence on breastfeeding duration in adolescent mothers. Breastfeed Med. 2010;5(1):41-7.

45. Hoddinott P, Craig L, Maclennan G, Boyers D, Vale L. NHS Grampian and the University of Aberdeen FEST Project Team. The FEeding Support Team (FEST) randomised, controlled feasibility trial of proactive and reactive telephone support for breastfeeding women living in disadvantaged areas. BMJ Open. 2012;2(2):e000652.

46. Simonetti V, Palma E, Giglio A, Mohn A, Cicolini G. A structured telephonic counselling to promote the exclusive breastfeeding of healthy babies aged zero to six months: a pilot study. Int J Nurs Pract. 2012;18(3):289-94.

47. Forster DA, McLardie-Hore FE, McLachlan HL, Davey MA, Grimes HA, Dennis $\mathrm{CL}$, et al. Proactive peer (mother-to-mother) breastfeeding support by telephone (ringing up about breastfeeding early [RUBY]): a multicentre, unblinded, randomised controlled trial. E Clinical Medicine. 2019;8:20-8.

48. Menon P, Nguyen PH, Saha KK, Khaled A, Kennedy A, Tran LM, et al. Impacts on breastfeeding practices of at-scale strategies that combine intensive interpersonal counseling, mass media, and community mobilization: results of cluster-randomized program evaluations in Bangladesh and Viet Nam. PLoS Med. 2016;13(10):e1002159.

\section{Publisher's Note}

Springer Nature remains neutral with regard to jurisdictional claims in published maps and institutional affiliations.

Ready to submit your research? Choose BMC and benefit from:

- fast, convenient online submission

- thorough peer review by experienced researchers in your field

- rapid publication on acceptance

- support for research data, including large and complex data types

- gold Open Access which fosters wider collaboration and increased citations

- maximum visibility for your research: over $100 \mathrm{M}$ website views per year

At $\mathrm{BMC}$, research is always in progress.

Learn more biomedcentral.com/submissions 